\title{
Fuel selection at the level of mitochondria in mammalian tissues
}

\author{
BY RICHARD M. DENTON \\ Department of Biochemistry, University of Bristol, School of Medical Sciences, University Walk, \\ Bristol BS8 ITD \\ AND JAMES G. MCCORMACK \\ Department of Pharmacology, Syntex Research Centre, Heriot-Watt University Research Park, \\ Riccarton, Edinburgh EH14 4AP
}

\section{Sélection de substrats énergétiques au niveau des mitochondries dans les tissus de mammifères}

\section{RÉSUMÉ}

Dans la plupart des cellules de mammifères, les mitochondries sont de loin le site le plus important de production d'ATP. Ceci résulte du processus de phosphorylation oxydative. Les substrats dans ce processus peuvent être l'acyl gras-CoA dérivé de triacylglycérols et autres lipides, le pyruvate dérivé du glucose et autres glucides, et toute une variété d'oxo-acides dérivés d'acides aminés. Cette première contribution au symposium sera concentrée sur deux questions étroitement liées: Quels sont les mécanismes qui déterminent le choix du substrat énergétique à oxyder, et comment l'ensemble du processus de phosphorylation oxydative correspond-il aux besoins de la cellule?

Les voies impliquées dans l'oxydation des principaux substrats de la mitochondrie peuvent être représentées selon le schéma suivant:

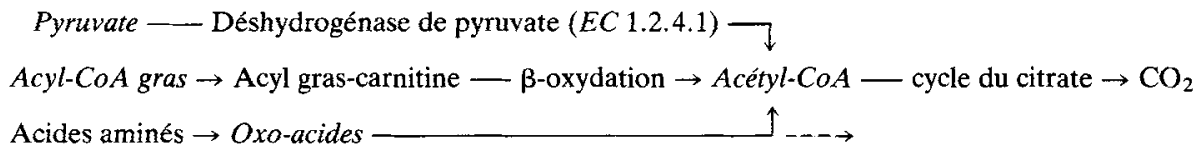

Toutes ces voies forment du $\mathrm{NADH}$ ou du $\mathrm{FADH}_{2}$ qui apportent des équivalents réducteurs à la chaîne respiratoire; le transfert d'électrons par la chaîne est alors lié à la synthèse d'ATP à partir d'ADP et de phosphate inorganique, par la génération d'une force proton-motive à travers la membrane mitochondriale interne. La régulation de ces voies est complexe et implique une combinaison de modifications dans l'apport de substrats avec un contrôle exercé au niveau de la mitochondrie. Ce contrôle s'exerce à des stades précoces dans les voies de l'utilisation de l'acyl-CoA, du pyruvate et des oxo-acides à chaîne ramifiée (dérivés de leucine, isoleucine, et valine). Ce sont la carnitine acyl gras transférase 1 (EC 2.3.1.21; CNAT-1), la pyruvate déshydrogénase $(\mathrm{PDH})$ et la déshydrogénase d'oxo-acide à chaîne ramifiée $(E C$ 1.2.4.4; BCOADH). Dans son ensemble, la régulation de ces enzymes est critique dans la sélection des substrats. Le taux total de l'apport de pouvoir réducteur à la chaîne respiratoire est également largement déterminé par ces trois enzymes avec la déshydrogénase de NAD-isocitrate $(E C$ 1.1.1.41) et la déshydrogénase d'oxoglutarate $(E C$ 1.2.4.2) qui 
régulent le cycle du citrate. Les propriétés régulatrices de ces enzymes seront étudiées l'une après l'autre. Un intérêt particulier sera accordé à la régulation du PDH par phosphorylation réversible, et à son rôle dans la sélection des substrats. L'augmentation de l'activité PHD-kinase ( $E C$ 2.7.1.99) est importante en ce qu'elle limite l'utilisation du pyruvate en cas de nécessité, comme dans le jeûne où des hormones telles que l'insuline ou celles qui élèvent les niveaux de $\mathrm{Ca}^{2+}$ dans la cellule agissent par la phosphatase-PDH (EC 3.1.3.43; bien que par des mécanismes différents). L'importance relative du contrôle de l'ensemble de la production d'ATP par les mitochondries par des modifications dans les taux d'ATP:ADP ou par des augmentations du $\mathrm{Ca}^{2+}$ des mitochondries sera également discutée.

An average human adult contains about $50 \mathrm{~g}$ ATP at any one instant, whereas the adult's typical energy needs over $24 \mathrm{~h}$ requires the hydrolysis of over 4000 times this amount, or $200 \mathrm{~kg}$ ATP! Moreover, utilization of ATP varies greatly in different tissues in different circumstances. For instance, a person doing strenuous exercise will require their heart to work up to six times harder than at rest. Such changes require matching increases in respiration and, hence, ATP formation and it is important that the appropriate metabolic fuel is used depending on the nutritional status of the individual and the tissue.

In most tissues, mitochondria are by far the most important sites of ATP production. This involves the process of oxidative phosphorylation. The main substrates for oxidative phosphorylation are fatty acyl-CoA derived from triacylglycerol and other lipids, pyruvate derived from glucose, glycogen and other carbohydrates and a range of oxo-acids derived from amino acids and protein (Fig. 1). The present article is concerned with two closely inter-related questions. What are the mechanisms in mitochondria which determine the choice of substrate to be oxidized and how is the overall process of oxidative phosphorylation matched to the needs of the cell?

The selection of the appropriate substrates for oxidation requires a complex array of regulatory mechanisms. Some of these act at an extramitochondrial level and determine the supply of pyruvate, fatty acyl-CoA and amino acid-derived oxo-acids for mitochondrial metabolism. Important examples include glucose transport into cells and the breakdown of glycogen, triacylglycerol and protein. These are beyond the scope of the present article which focuses on the mechanisms involved in the control of the formation of acetyl-CoA (and hence $\mathrm{CO}_{2}$ ) in mitochondria from pyruvate, fatty acyl-CoA and amino acid-derived oxo-acids (Fig. 2(a)). Regulation is exerted through alterations in the activity of enzymes involved in early steps in the pathways of pyruvate and fatty acyl-CoA utilization, namely pyruvate dehydrogenase $(E C$ 1.2.4.1; $\mathrm{PDH})$ and longchain carnitine acyl-transferase-1 (EC 2.3.1.21; CNAT-1). The situation with the range of oxo-acids derived from the amino acids is necessarily more complicated and we will only consider the regulation of branched-chain oxo-acid dehydrogenase (EC 1.2.4.4; $\mathrm{BCOADH}$ ) which governs the metabolism of three oxo-acids, derived from valine, leucine and isoleucine. The overall supply of reducing equivalents in the form of NADH and $\mathrm{FADH}_{2}$ to the respiratory chain is largely determined by the activities of these three enzymes together with NAD-isocitrate dehydrogenase ( $E C$ 1.1.1.41; ICDH) and oxoglutarate dehydrogenase ( $E C$ 1.2.4.2; OGDH) which regulate the citrate cycle.

Regulatory mechanisms can be conveniently divided into different types: long-term, 'intrinsic' short-term and 'extrinsic' short-term. All five of the enzymes on which we are 


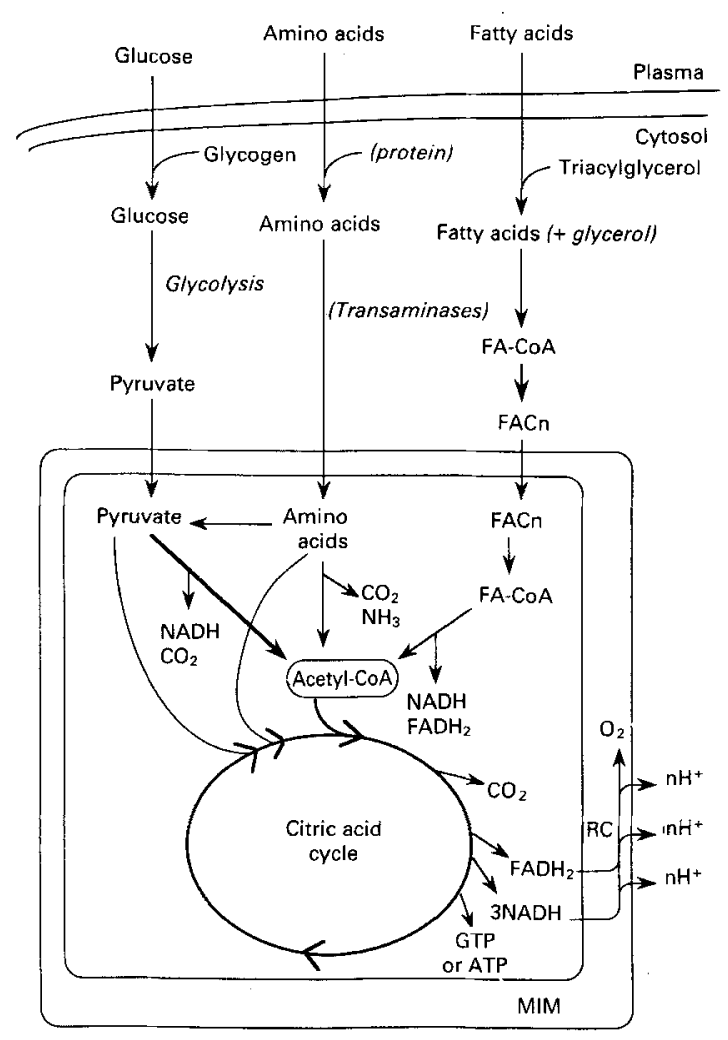

Fig. 1. Outline of oxidative metabolism in mammalian tissue cells. Metabolites derived from carbohydrate, protein and lipids are converted to the common intermediate acetyl-CoA which is then oxidized by the citrate cycle. The various pathways involved generate NADH and FADH which donate reducing equivalents to the respiratory chain. Transfer of these equivalents down the respiratory chain to $\mathrm{O}_{2}$ results in the pumping of protons across the mitochondrial inner membrane (MIM). The resultant proton-motive gradient is used to drive the synthesis of ATP from ADP plus phosphate. RC, respiratory chain; FA, fatty acid; Cn, carnitine; Pi, phosphate.

concentrating in the present article are regulated by more than one type of mechanism, with the PDH system being regulated by all three types (Fig. 2(b)).

It should be noted that mitochondria are the site of a number of other metabolic pathways which can have a bearing on fuel selection because the pathways are concerned with the interconversion of fuels. For example, the conversion of acetyl-CoA to hydroxymethylglutaryl-CoA and to citrate are intramitochondrial steps involved in the synthesis of ketone bodies from fatty acids in the liver or the synthesis of fatty acids from carbohydrate in lipogenic tissues respectively (Fig. 2(a)).

\section{THE REGULATION OF ACETYL-COA FORMATION FROM LONG-CHAIN FATTY ACYL-COA}

Fatty acyl-CoA formed in the cytoplasm from long-chain fatty acids is not transported directly across the inner mitochondrial membrane (Fig. 1). To enter the mitochondrial 


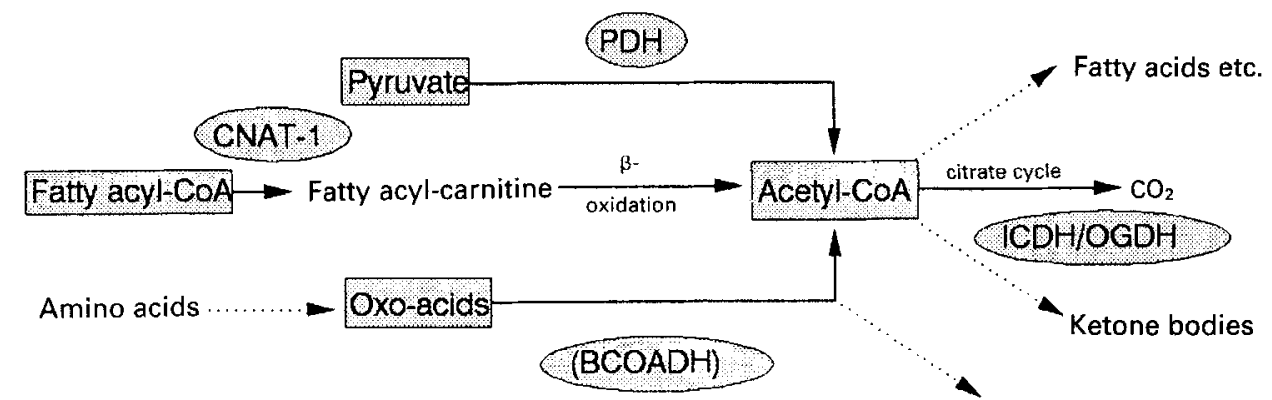

Fig. 2. The principal enzymes involved in the regulation of fuel selection in mitochondria. Pyruvate dehydrogenase $(E C$ 1.2.4.1; PDH), long-chain carnitine acyl-transferase-1 (EC 2.3.1.21; CNAT-1), branchedchain oxo-acid dehydrogenase $(E C$ 1.2.4.4; BCOADH), NAD-isocitrate dehydrogenase $(E C$ 1.1.1.41; ICDH) and oxoglutarate dehydrogenase $(E C$ 1.2.4.2; $\mathrm{OGDH})$. The types of regulation that have been observed are summarized as follows:

\begin{tabular}{lccc}
\hline & & Short-term regulation $\dagger$ \\
Enzyme system & $\begin{array}{c}\text { Long-term } \\
\text { regulation* }\end{array}$ & Intrinsic & Extrinsic \\
\hline BCOADH & $\star$ & $\star$ & $?$ \\
CNAT-1 & $\star$ & $\star$ & $\vdots$ \\
PDH & $\star$ & $\star$ & $\star$ \\
NAD-ICDH & $?$ & $\star$ & $\star$ \\
OGDH & $?$ & $\star$ \\
\hline
\end{tabular}

* Long-term regulation takes hours and involves changes in amount of enzyme (or regulatory protein) usually through alterations in gene expression.

$\uparrow$ Short-term regulation takes a few minutes at most and can be subdivided into 'intrinsic' (control through changes by intracellular metabolites) and 'extrinsic' (control exerted by extracellular agents, usually hormones).

matrix where conversion to acetyl-CoA by $\beta$-oxidation takes place, the activated fatty acid is first transferred to carnitine to form fatty acyl-carnitine by the enzyme carnitine acyl-transferase-1 (CNAT-1) which is largely located on the outer membrane of mitochondria. There is then a specific transport system in the inner mitochondrial membrane which exchanges matrix carnitine for external long-chain fatty acyl-carnitine and then a second carnitine acyl-transferase (CNAT-2) apparently located on the inside of the inner membrane catalyses the regeneration of fatty acyl-CoA which is the substrate for $\beta$-oxidation (McGarry \& Foster, 1980).

The rate of fatty acid oxidation seems to be largely determined by substrate supply and this is in keeping with fatty acids being the preferred fuel for respiration in many circumstances. However, control can also be exerted at the level of CNAT-1 (McGarry \& Foster, 1980; Schulz, 1991; Brady et al. 1993). In particular, this enzyme which has been cloned recently (Esser et al. 1993) is subject to inhibition by malonyl-CoA (McGarry \& Foster, 1980). Malonyl-CoA is the product of acetyl-CoA carboxylase ( $E C$ 6.4.1.2), the step which determines rates of fatty acid synthesis; thus, regulation by malonyl-CoA is a typical intrinsic short-term mechanism which prevents fatty acid oxidation and synthesis occurring wastefully at the same time. There has been consider- 
able debate as to whether or not malonyl-CoA binds directly to CNAT- 1 or to a separate regulatory subunit (Brady et al. 1993; Esser et al. 1993). The balance of evidence favours direct binding. In the longer term, mechanisms exist which result in changes in the overall activity of CNAT-1 as well as its sensitivity to malonyl-CoA (Kolodzief \& Zammit, 1990). In particular, in starvation, when rates of fatty acid oxidation are enhanced in liver and other tissues, the activity of the enzyme is increased and its apparent sensitivity to inhibition by malonyl-CoA decreased.

\section{THE REGULATION OF ACETYL-COA FORMATION FROM OXO-ACIDS DERIVED FROM LEUCINE, ISOLEUCINE AND VALINE}

In man and other mammals, the three branched-chain amino acids are essential and, therefore, dietary requirements are closely linked to rates of degradation. All three amino acids are common constituents of proteins and together account for about $20 \%$ of protein. Metabolism involves transamination to the corresponding three oxo-acids (4-methyl-2-oxopentanoate, 3-methyl-oxopentanoate and 3-methyl-2-oxobutyrate) which are all substrates of the BCOADH complex which regulates the rate of complete degradation to acetyl-CoA and other endproducts (Randle et al. 1987). The activity of this complex is largely responsible for keeping circulatory levels of the branched-chain amino acids reasonably constant despite changes in the protein content of the diet or starvation. In Maple Syrup Urine Disease, there is a massive increase in the $K_{m}$ of the complex for the branched-chain oxo-acids and as a consequence the plasma concentrations of the branched-chain amino acids can increase by up to 100 -fold resulting in the risk of severe brain damage.

The BCOADH complex is similar in structure and mechanism to the pyruvate and oxoglutarate dehydrogenase complexes. All three complexes are composed of a central symmetrical core of E2 (acyl-transferase) subunits around which are arranged multiple copies of E1 (decarboxylase) and E3 (lipoate dehydrogenase) subunits (Yeaman, 1989). Regulation of the overall activity of these complexes is brought about through changes in the activity of the E1 subunits which catalyse the decarboxylation of the appropriate oxo-acid.

In the case of the BCOADH complex, regulation can occur by a number of different mechanisms. Activity may be inhibited by the build-up of the endproducts of the reaction catalysed by the complex, i.e. NADH and the branched-chain acyl-CoA, but the most important means of control is through reversible phosphorylation of the E1 subunits brought about by a unique kinase and phosphatase (Fig. 3; Randle et al. 1987; Yeaman, 1989; Popov et al. 1992). Alterations in kinase activity are important in determining the proportion of the complex in its active non-phosphorylated form. For example, accumulation of the branched-chain oxo-acids inhibits the kinase and, thus, leads to the dephosphorylation and, hence, activation of BCOADH. This mechanism may partly explain the increases in activity of the complex (especially in the liver) observed when animals are transferred from a low- to a high-protein diet. However, alterations in the protein content of the diet also cause long-term adaptive changes in the activity of the kinase (Randle et al. 1987) which are important in increasing liver BCOADH activity with increasing dietary protein. Tissues other than liver contain appreciable amounts of $\mathrm{BCOADH}$ including heart and skeletal muscle. However, unlike liver the complex in these other tissues is mostly phosphorylated and, hence, inactive under normal dietary 
(a)

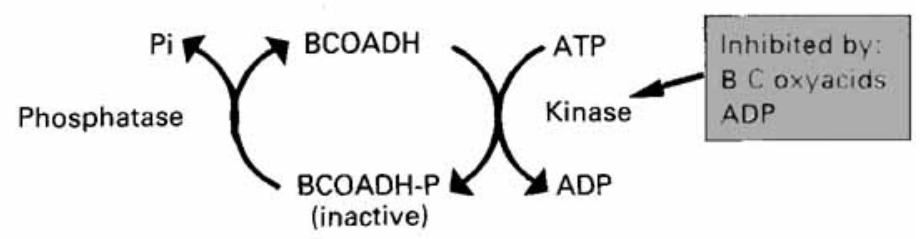

(b)

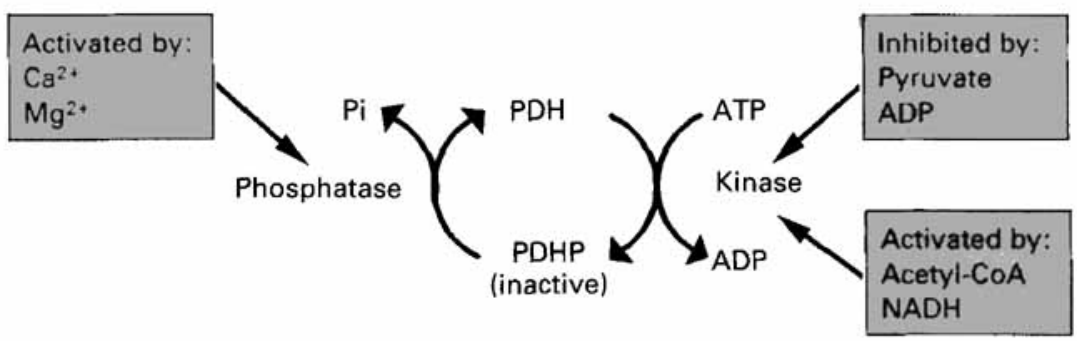

Fig. 3. Short-term regulation of (a) branched-chain oxo-acid dehydrogenase (EC 1.2.4.4; BCOADH) and (b) pyruvate dehydrogenase ( $E C$ 1.2.4.1; $\mathrm{PDH}$ ) complexes by reversible phosphorylation. In addition the activity of the non-phosphorylated forms of both complexes is subject to endproduct inhibition by accumulation of $\mathrm{NADH}$ and/or appropriate acyl-CoA. Pi, phosphate.

conditions (Randle et al. 1987; Yeaman, 1989), apparently because of relatively high activities of the kinase. The recent molecular cloning and expression of the kinase (Popov et al. 1992) should facilitate future work into the basis of the long-term regulation of this enzyme and provide an explanation for the marked differences in activity in different tissues.

\section{THE REGULATION OF ACETYL-COA FORMATION FROM PYRUVATE}

The pyruvate dehydrogenase $(\mathrm{PDH})$ complex which catalyses the formation of acetyl$\mathrm{CoA}$ from pyruvate is a very important site of regulation of carbohydrate metabolism. Since carbohydrate cannot be regenerated from acetyl-CoA in man and other animals, this enzyme complex dictates the rate of carbohydrate utilization. The major fates of pyruvate are oxidation to $\mathrm{CO}_{2}$ or conversion to fatty acids depending on tissue and circumstances (Denton \& Halestrap, 1979). The PDH complex is structurally related to the BCOADH complex and its regulation also shows some similarities but is even more complicated because of the multiple roles of the enzyme.

First, the PDH complex is regulated by intrinsic short-term mechanisms by various intracellular metabolites including its substrates and products. The complex exhibits endproduct inhibition by $\mathrm{NADH}$ and acetyl-CoA and also regulation by reversible phosphorylation (Fig. 3). The specific kinase which converts the complex to a completely inactive form by phosphorylating the E1 $\alpha$ subunits is subject to a number of different intrinsic regulations. These include activation of kinase activity with increasing ATP:ADP, acetyl-CoA:CoA and NADH:NAD ${ }^{+}$values and inhibition of kinase activity by increasing pyruvate concentrations (Denton \& Halestrap, 1979; Randle, 1986; Behal et al. 1993). These intrinsic types of regulation are an important means of ensuring that 
Table 1. Hormonal regulation of pyruvate dehydrogenase (EC 1.2.4.1) activity (\% present in active non-phosphorylated form) in rat adipose and heart tissue (Results taken from McCormack \& England (1983), Denton et al. (1984) and R. M. Denton and J. G. McCormack, (unpublished results))

\begin{tabular}{|c|c|c|}
\hline & $\begin{array}{l}\text { Rat epididymal } \\
\text { adipose tissue }\end{array}$ & $\begin{array}{l}\text { Perfused } \\
\text { rat heart }\end{array}$ \\
\hline No additions & 20 & 10 \\
\hline Insulin & 50 & 10 \\
\hline Isoproterenol & 15 & 46 \\
\hline Isoproterenol+insulin & 30 & - \\
\hline $\mathrm{Ca}$ (plus $5 \mathrm{~mm}$ ) & 39 & 46 \\
\hline Increased work-load & - & 36 \\
\hline
\end{tabular}

the activity of the PDH complex is appropriate. For example, they largely explain the marked increase in activity which is observed when cell ATP:ADP values are lowered, and the marked decrease in activity which is associated with enhanced fatty acid oxidation (because of increases in intramitochondrial acetyl-CoA:CoA values).

The activity of the complex can also be regulated by important extrinsic short-term and long-term mechanisms. In starvation, it is vital in mammals that the modest amounts of carbohydrate stored mainly as glycogen are conserved by blocking the activity of PDH. Extensive studies by Randle and colleagues (Randle, 1986) have shown that this involves not only the intrinsic short-term mechanisms associated with increased fatty acid oxidation just described but also long-term increases in the activity of the kinase. The mechanisms that may be involved are described in detail by Randle (1995).

The PDH complex may also be regulated in the short-term by hormones. We find this area to be particularly fascinating because it involves signal transduction not only across the cell membrane but also across the inner mitochondrial membrane. The most studied examples are the activation of the PDH complex in fat cells exposed to insulin and in the heart and other tissues by hormones which act through increases in cytoplasmic $\mathrm{Ca}^{2+}$ concentrations. Examples are given in Table 1. It should be noted that the activating effect of insulin is restricted to lipogenic tissues and, hence, is not observed in the heart, whereas the activating effect of the $\beta$-agonist isoproterenol is not evident in fat cells (presumably because there is no increase in cytoplasmic $\mathrm{Ca}^{2+}$ ). These short-term hormonal effects are brought about by increases in the activity of the $\mathrm{PDH}$ phosphatase, but by different means. As will be described in further detail in the next section, hormones which act through increasing the cytoplasmic $\mathrm{Ca}^{2+}$ concentration (such as isoproterenol on the heart) activate the phosphatase through elevations in the mitochondrial concentrations of $\mathrm{Ca}^{2+}$. In contrast, the mechanisms involved in the activation of the phosphatase in fat cells incubated with insulin are less well understood (Denton et al. 1989).

Insulin greatly enhances the conversion of glucose to fatty acids by fat cells through the parallel activation of glucose transport, $\mathrm{PDH}$ and acetyl-CoA carboxylase. The activation of PDH is due to an increased proportion of the complex being present in its dephosphorylated form. The activation following exposure of fat cells to insulin persists during the preparation and subsequent incubation of mitochondria (Denton et al. 1984). It can still be observed in mitochondria prepared from insulin-treated tissue and then 
made permeable to all substances up to a molecular weight of about 2000 by controlled treatment with toluene (Thomas \& Denton, 1986; Thomas et al. 1986). Full extraction of the mitochondria results in the complete loss of the persistent effect of insulin. These studies revealed that insulin acts by causing a decrease in the apparent $K_{m}$ of the phosphatase for $\mathrm{Mg}^{2+}$. The major mystery is the signalling system linking the insulin receptor on the cell membrane to the phosphatase within the mitochondrial matrix. Our present working hypothesis is that the system results in a change in the interaction of the PDH system, including the phosphatase, with a large intramitochondrial component, with this interaction being lost on complete lysis of the mitochondria (but not with toluene permeabilization). An attractive idea is that this component may exist in the inner membrane and, thus, could perhaps be influenced by cytosolic events (Denton et al. 1984, 1989).

Studies in many laboratories have suggested that at least some of the intracellular effects of insulin result from the activation of a serine protein kinase cascade which results in the activation of mitogen-activated protein kinase (Cohen, 1993). This cascade may be initiated by the occupied insulin receptor phosphorylating insulin-receptor substrate 1 on tyrosine residues which indirectly leads to increases in the proportion of Ras containing bound GTP and, hence, to an activation of Raf 1 which is the first kinase in the cascades (Myers et al. 1994). The involvement of this system in the activation of $\mathrm{PDH}$ is doubtful, as there is very poor correlation between the activation of PDH and that of MAP kinase under a variety of conditions (N. Edgell, K. Moule and R. M. Denton, unpublished results).

Molecular cloning of the specific phosphatase and kinase involved in the reversible phosphorylation of PDH has been achieved recently (Lawson et al. 1993; Popov et al. 1993). This should greatly aid future studies into the molecular basis of the long-term regulation of the kinase in insulin-deficient states such as starvation, as well as the short-term regulation of the phosphatase in adipose and other lipogenic tissues by insulin.

\section{REGULATION OF CITRATE CYCLE AND OVERALL MITOCHONDRIAL ATP SYNTHESIS}

The main sites of regulation of the citrate cycle appear to be NAD-isocitrate dehydrogenase (NAD-ICDH) and the oxoglutarate dehydrogenase complex (OGDH). Regulation of these two enzymes is quite similar and involves both intrinsic and extrinsic types of control; neither enzyme is regulated by reversible phosphorylation.

The most important example of intrinsic control is the inhibition of both enzymes by increasing ATP:ADP and NADH:NAD ${ }^{+}$values (McCormack \& Denton, 1979; Gabriel et al. 1986; Rutter \& Denton, 1988; Rutter, 1990). Clearly these controls could form the basis of matching the rate of the citrate cycle to the ATP needs of the cell (McCormack et al. 1990). Thus, when ATP utilization is increased, the concentration of ADP might be expected to rise and this would stimulate the production of NADH for the respiratory chain by activating NAD-ICDH and OGDH; PDH may also be activated under these conditions. This mechanism is illustrated in Fig. 4. The mechanism is likely to be important in some circumstances, for example in stimulated skeletal muscle (Radda et al. 1993), but in many other stimulated tissues it has been difficult to demonstrate any increase in ADP (Denton \& McCormack, 1990; McCormack et al. 1990). 


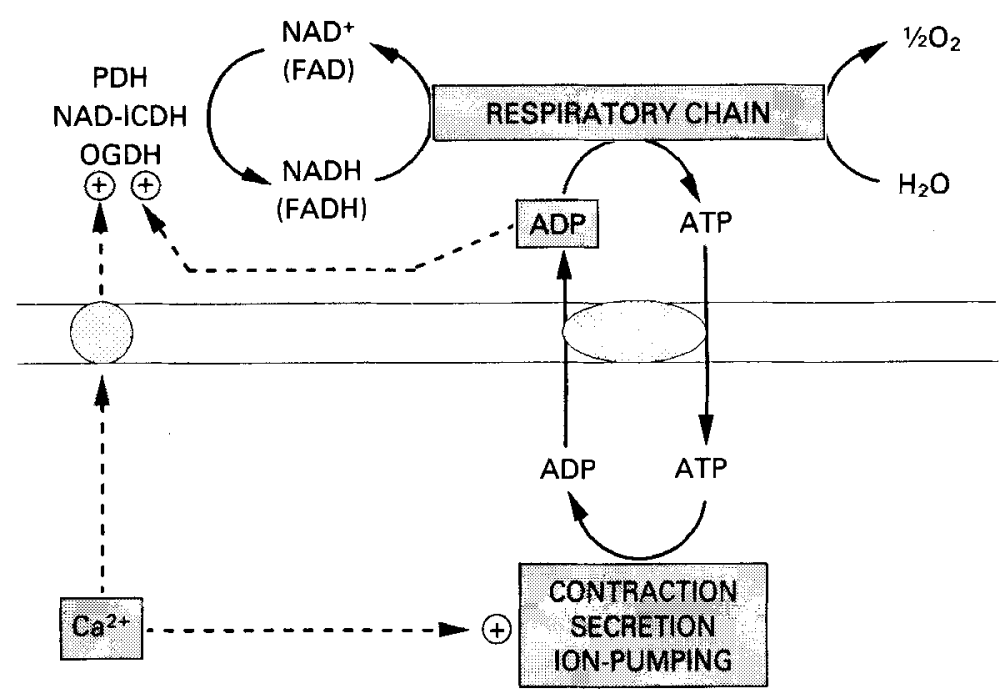

Fig. 4. Regulation of overall respiration. In tissues with adequate substrate and $\mathrm{O}_{2}$ supply increases in mitochondrial ATP production required to match increases in ATP utilization may be brought about either by increases in $\mathrm{Ca}^{2+}$ or ADP or a combination of both. PDH, pyruvate dehydrogenase $(E C$ 1.2.4.1); NAD-ICDH, NAD-isocitrate dehydrogenase $(E C$ 1.1.1.41); OGDH, oxoglutarate dehydrogenase (EC 1.2.4.2).

Well-studied examples of the latter situation are the stimulations which follow exposure of the heart to $\beta$-adrenergic agonists (such as isoproterenol) and of the liver to $\alpha_{1}$-adrenergic agonists or vasopressin (for detailed reviews, see Denton \& McCormack, 1990; McCormack et al. 1990). Under these conditions, there is now strong evidence that increases in cytoplasmic $\mathrm{Ca}^{2+}$ result in increases in mitochondrial $\mathrm{Ca}^{2+}$ which activate both NAD-ICDH and OGDH and also PDH by activating PDH phosphatase (Table 1 and Fig. 4).

We have shown all three enzymes to be activated by $\mathrm{Ca}^{2+}$ in the micromolar range with ICDH somewhat less sensitive than the other two dehydrogenase systems (Denton et al. 1972, 1978; McCormack \& Denton, 1979; Rutter \& Denton, 1988). Detailed studies on isolated mitochondria indicate that increases in extramitochondrial $\mathrm{Ca}^{2+}$ within the physiological range cause increases in intramitochondrial $\mathrm{Ca}^{2+}$ which are sufficient to activate the dehydrogenases (McCormack \& Denton, 1994).

A number of approaches have been developed which demonstrate the importance of $\mathrm{Ca}^{2+}$ in the regulation of mitochondrial metabolism within intact cell preparations (Denton \& McCormack, 1990; McCormack \& Denton, 1994). These approaches include:

(a) the use of ruthenium red which more or less specifically inhibits $\mathrm{Ca}^{2+}$ uptake into mitochondria when applied to the rat heart. In the presence of ruthenium red, $\beta$-adrenergic agonists still stimulate heart contraction and $\mathrm{O}_{2}$ uptake but the activation of PDH is no longer evident and there is a decrease in ATP:ADP value (McCormack \& England, 1983; Unitt et al. 1989; McCormack et al. 1990);

(b) the rapid preparation of mitochondria under conditions which block both uptake and efflux of $\mathrm{Ca}^{2+}$. Enhanced activities of both PDH and OGDH can be demonstrated if the 
mitochondria are prepared from stimulated tissue and these enhanced activities can be shown to be due to increased intramitochondrial concentrations of $\mathrm{Ca}^{2+}\left(\mathrm{McCormack}^{2}\right.$ Denton, 1984; McCormack et al. 1990);

(c) direct measurement of $\mathrm{Ca}^{2+}$ within mitochondria of intact cell preparations. Three different approaches have been developed recently (Miyata et al. 1991; Allen et al. 1992; Rizzuto et al. 1992). All three approaches indicate that in unstimulated cells the mitochondrial $\mathrm{Ca}^{2+}$ concentration is about $0.1 \mu \mathrm{M}$ and that is increased to about $0.5 \mu \mathrm{M}$ in cells stimulated maximally by agents which increase cytosolic $\mathrm{Ca}^{2+}$. The intramitochondrial dehydrogenases will be activated over this range of concentration.

Overall there is now overwhelming evidence showing that increases in mitochondrial $\mathrm{Ca}^{2+}$ concentrations are important in the stimulation of mitochondrial respiration and ATP synthesis in heart and liver. The effects may not be confined only to the three $\mathrm{Ca}^{2+}$-sensitive dehydrogenases. Increases in mitochondrial $\mathrm{Ca}^{2+}$ will also inhibit matrix pyrophosphatase which can influence mitochondrial volume and, hence, the activities of $\beta$-oxidation, glutaminase and the respiratory chain in the liver (Halestrap, 1989). It has also been suggested that the mitochondrial ATP synthetase system is sensitive to $\mathrm{Ca}^{2+}$ (Harris \& Das, 1991), but direct effects of $\mathrm{Ca}^{2+}$ on this system have not been clearly demonstrated.

In summary, when $\mathrm{O}_{2}$ and substrate supply is adequate, respiration and, hence, rates of ATP formation can be regulated by two main mechanisms: intrinsically by increases in ADP or extrinsically by increases in $\mathrm{Ca}^{2+}$ (Fig. 4). The advantage of the latter form of regulation is that it allows respiration to be stimulated under conditions where ATP utilization is elevated because of increases in muscle contraction, ion-pumping, secretion etc. without the need for the critical ATP:ADP and NADH:NAD ${ }^{+}$values to be decreased. One of the challenges for the future is to establish the relative roles of these two potential mechanisms in a far greater variety of conditions and tissues. There is indirect evidence indicating a role for changes in mitochondrial $\mathrm{Ca}^{2+}$ concentrations in brain, skeletal muscle, white and brown adipose tissue, kidney, lymphocytes, adrenal cortical cells and pancreatic $\beta$-cells (as well as the much more extensive evidence in heart and liver; Denton \& McCormack, 1985; McCormack et al. 1990).

Studies carried out in the authors' laboratories were supported by grants from the Medical Research Council, The British Diabetic Association, the British Heart Foundation and the Lister Institute of Preventive Medicine.

\section{REFERENCES}

Allen, S. P., Stone, D. \& McCormack, J. G. (1992). The loading of Fura-2 into mitochondria in the intact perfused rat heart and its use to estimate matrix $\mathrm{Ca}^{2+}$ under various conditions. Journal of Molecular Cardiology 24, 765-773.

Behel, R. H., Buxton, D. B., Robertson, J. G. \& Olson, M. S. (1993). Regulation of the pyruvate dehydrogenase multienzyme complex. Annual Review of Nutrition 13, 497-520.

Brady, P. S., Ramsay, R. R. \& Brady, L. J. (1993). Regulation of the long-chain carnitine acyltransferases. FASEB Journal 7, 1039-1044.

Cohen, P. (1993). Dissection of the protein phosphorylation cascades involved in insulin and growth factor action. Biochemical Society Transactions 21, 533-567.

Denton, R. M. \& Halestrap, A. P. (1979). Regulation of pyruvate metabolism in mammalian tissues. Essays in Biochemistry 15, 37-77.

Denton, R. M. \& McCormack, J. G. (1985). $\mathrm{Ca}^{2+}$-transport by mammalian mitochondria and its role in hormone action. American Journal of Physiology 249, E543-E554. 
Denton, R. M. \& McCormack, J. G. (1990). $\mathrm{Ca}^{2+}$ as a second messenger within mitochondria of the heart and other tissues. Annual Review of Physiology 52, 451-466.

Denton, R. M., McCormack, J. G. \& Marshall, S. E. (1984). Persistence of the effect of insulin on pyruvate dehydrogenase activity in rat white and brown adipose tissue during the preparation and subsequent incubation of mitochondria. Biochemical Journal 217, 441-452.

Denton, R. M., Midgley, P. J. W., Rutter, G. A., Thomas, A. P. \& McCormack, J. G. (1989). Studies into the mechanism whereby insulin activates pyruvate dehydrogenase complex in adipose tissue. Annals of the New York Academy of Sciences 573, 285-296.

Denton, R. M., Randle, P. J. \& Martin, B. R. (1972). Stimulation by calcium ions of pyruvate dehydrogenase phosphatase. Biochemical Journal 128, 161-163.

Denton, R. M., Richards, D. A. \& Chin, J. G. (1978). Calcium ions and the regulation of NAD -linked $^{+}$ isocitrate dehydrogenase from the mitochondria of rat heart and other tissues. Biochemical Journal 176, $899-906$.

Esser, V., Britton, C. H., Weis, B. C., Foster, D. W. \& McGarry, J. D. (1993). Cloning, sequencing and expression of a cDNA encoding rat liver mitochondrial carnitine palmitoyltransferase 1. Journal of Biological Chemistry 288, 5817-5822.

Gabriel, J. L., Zervos, P. R. \& Plaut, G. W. E. (1986). Activity of purified NAD-specific isocitrate dehydrogenase at modulator and substrate concentrations approximating conditions in mitochondria. Metabolism 35, 661-667.

Halestrap, A. P. (1989). The regulation of the mitochondrial matrix volume in vivo and in vitro and its role in the control of mitochondrial metabolism. Biochimica et Biophysica Acta 973, 355-382.

Harris, D. A. \& Das, A. M. (1991), Control of mitochondrial ATP synthesis in the heart. Biochemical Journal 280, 501-573.

Kolodzief, M. P. \& Zammit, V. A. (1990). Re-evaluation of the interaction of malonyl-CoA with the rat liver mitochondrial carnitine palmityltransferase system by using purified outer membranes. Biochemical Journal 267, 85-90.

Lawson, J. E., Niu, X. D., Browning, K. S., Trong, H. L., Yan, J. G. \& Reed, L. J. (1993). Molecular cloning and expression of the catalytic subunit of bovine pyruvate dehydrogenase phosphatase and sequence similarity to protein phosphatase 2C. Biochemistry 32,8987-8993.

McCormack, J. G. \& Denton, R. M. (1979). The effects of calcium ions and adenine nucleotides on the activity of pig heart 2-oxoglutarate dehydrogenase complex. Biochemical Journal 180, 533-544.

McCormack, J. G. \& Denton, R. M. (1984). Role of $\mathrm{Ca}^{2+}$ ions in the regulation of intramitochondrial metabolism in rat heart. Evidence from studies with isolated mitochondria that adrenaline activates the pyruvate and 2-oxoglutarate dehydrogenase complexes by increasing the intramitochondrial concentration of $\mathrm{Ca}^{2+}$. Biochemical Journal 218, 235-247.

McCormack, J. G. \& Denton, R. M. (1994). Signal transduction by intramitochondrial $\mathrm{Ca}^{2+}$ in mammalian energy metabolism. News in Physiological Science 9, 71-76.

McCormack, J. G. \& England, P. J. (1983). Ruthenium red inhibits the activation of pyruvate dehydrogenase caused by positive isotropic agents in the perfused rat heart. Biochemical Joumal 214, 581-585.

McCormack, J. G., Halestrap, A. P. \& Denton, R. M. (1990). The role of calcium ions in the regulation of mammalian intramitochondrial metabolism. Physiological Reviews 70, 391-425.

McGarry, J. D. \& Foster, D. W. (1980). Regulation of hepatic fatty acid oxidation and ketone body production. Annual Review of Biochemistry 49, 395-420.

Miyata, H., Silverman, H. S., Sollott, S. J., Lakatta, E. G., Stern, M. D. \& Hansford, R. G. (1991). Measurement of mitochondrial free $\mathrm{Ca}^{2+}$ concentration in living single rat cardiac myocytes. American Journal of Physiology 261, H1123-H1134.

Myers, M. G., Sun, X. J. \& White, J. F. (1994). The IRS-1 signaling system. Trends in Biochemical Sciences 19, 269-307.

Popov, K. M., Kedishvili, N. Y., Zhao, Y., Shimomura, Y., Grabb, D. W. \& Harris, R. A. (1993). Primary structure of pyruvate dehydrogenase kinase establishes a new family of eukaryotic protein kinases. Journal of Biological Chemistry 268, 26602-26606.

Popov, K. M., Zhao, Y., Shimomura, Y., Kuntz, M. J. \& Harris, R. A. (1992). Branched-chain alpha-keto acid dehydrogenase kinase in molecular cloning, expression and sequence similarity with histidine protein kinases. Journal of Biological Chemistry 267, 13127-13130.

Radda, G. K., Kemp, G. J., Syles, P. \& Taylor, D. J. (1993). Control of oxidative phosphorylation in muscle. Biochemical Society Transactions 21, 762-764.

Randle, P. J. (1986). Fuel selection in animals. Biochemical Society Transactions 14, 799-806. 
Randle, P. J. (1995). Metabolic fuel selection: general integration at the whole-body level. Proceedings of the Nutrition Society 54, 317-327.

Randle, P. J., Patston, P. A. \& Espinal, J. (1987). Branched-chain ketoacid dehydrogenase. The Enzymes 18B, 97-122.

Rizzuto, R., Simpson, A. W. M., Brini, M. \& Pozzan, T. (1992). Rapid changes of mitochondrial $\mathrm{Ca}^{2+}$ revealed by specifically targeted recombinant aequorin. Nature 358, 325-327.

Rutter, G. A. (1990). $\mathrm{Ca}^{2+}$-binding to citrate cycle dehydrogenases. International Journal of Biochemistry 22, 1081-1088.

Rutter, G. A. \& Denton, R. M. (1988). Regulation of NAD+-linked isocitrate dehydrogenase and 2-oxoglutarate dehydrogenase by $\mathrm{Ca}^{2+}$ ions within toluene permeabilized rat heart mitochondria. Interactions with regulation by adenine nucleotides and $\mathrm{NADH} / \mathrm{NAD}^{+}$ratios. Biochemical Journal 252, $181-189$.

Schulz, H. (1991). Beta oxidation of fatty acids. Biochimica et Biophysica Acta 1081, 109-120.

Thomas, A. P. \& Denton, R. M. (1986). Use of toluene-permeabilised mitochondria to study the regulation of pyruvate dehydrogenase in situ. Further evidence that insulin acts through stimulation of pyruvate dehydrogenase phosphatase. Biochemical Journal 238, 93-101.

Thomas, A. P., Diggle, T. A. \& Denton, R. M. (1986). Sensitivity of pyruvate dehydrogenase phosphate phosphatase to magnesium ions. Similar effects of spermine and insulin. Biochemical Journal 238, 83-91.

Unitt, J. F., McCormack, J. G., Reid, D., MacLachlan, L. K. \& England, P. J. (1989). Direct evidence for the role of intramitochondrial $\mathrm{Ca}^{2+}$ in the regulation of oxidative phosphorylation in the stimulated rat heart studies using P-31 NMR and ruthenium red. Biochemical Journal 262, 293-301.

Yeaman, S. J. (1989). The 2-oxo acid dehydrogenase complexes: recent advances. Biochemical Journal 257, $625-632$. 